\title{
NeuroBoricuas: a novel approach for incorporating neuroscience education in schools of Puerto Rico
}

\begin{abstract}
Bravo-Rivera, Christian ${ }^{a}$; Diaz-Ríos, Manuel ${ }^{\text {; }}$ Aldarondo-Hernández, Ariadna ; Santos-Vera, Bermary $^{\mathrm{b}}$; Ramos-Medina, Liorimark ${ }^{\mathrm{k}}$; De Jesús-Burgos, María Inés ${ }^{\mathrm{c}}$; Bravo-Rivera, Héctor ${ }^{\mathrm{d}}$; Torrado, Aranza ${ }^{\mathrm{d}}$; Cabezas-Bou, Ernesto ${ }^{\mathrm{d}}$; Cruz-Lopez, Fabiola ${ }^{\mathrm{e}}$; Colón-Mercado, Jennifer ${ }^{\mathrm{j}}$; Otero-Rivera, Jose ${ }^{\text {; }}$ Rolon-Reyes, Kimberleve ${ }^{\mathrm{d}}$; Mendez-Gonzalez, Miguel ${ }^{\mathrm{c}}$; Ferrer-Acosta, Yancy'; Zayas-Santiago, Astrid $^{\mathrm{l}}$; Tejeda, Flavia ${ }^{\mathrm{m}}$; Merced, Amelia ${ }^{\mathrm{c}}$; Quintero-Martinez, Zarcaly $^{\mathrm{g}}$; Landivar, Alicia ${ }^{\mathrm{k}}$; Colon-Cruz, Luis ${ }^{\mathrm{d}}$; Crooke-Rosado, Jonathan ${ }^{\mathrm{d}}$; Rivera-Aponte, David $^{\mathrm{m}}$; Acevedo-Canabal, Agnes ${ }^{\mathrm{d}}$; A Sosa-Lloréns, María ${ }^{\mathrm{d}}$; Quijano-Rivera, Eduardo ${ }^{\mathrm{h}}$.

${ }^{a}$ Department of Neuroscience, Cold Spring Harbor Laboratory, United States. ${ }^{b}$ Department of Physiology, Ponce School of Medicine and Health Sciences, Puerto Rico. ${ }^{\circ}$ Department of Biology, University of Puerto Rico, Puerto Rico. ${ }^{\mathrm{d} D e p a r t m e n t}$ of Anatomy and Neurobiology, University of Puerto Rico, Puerto Rico. ${ }^{\mathrm{e} D e p a r t m e n t}$ of Microbiology, University of Puerto Rico, Puerto Rico. ${ }^{f}$ Department of Computer Engineering, University of Puerto Rico, Puerto Rico. ${ }^{g}$ Department of Psychiatry, University of Puerto Rico, Puerto Rico. ${ }^{\mathrm{h} C}$ Community Service Center, Universidad Metropolitana de Puerto Rico, Puerto Rico. ${ }^{i}$ Carlos Albizu University, Puerto Rico. ${ }^{\mathrm{j}}$ Department of Physiology, University of Puerto Rico, Puerto Rico. ${ }^{\mathrm{k}}$ Estancia Montessori, Puerto Rico. ${ }^{\mathrm{l}}$ Department of Neuroscience, University Central del Caribe, Puerto Rico. ${ }^{\mathrm{m}}$ Department of Biochemistry, Universidad Central del Caribe, Puerto Rico.
\end{abstract}

\section{Abstract}

Puerto Rico is in dire need of transforming its education system to counter the current economic recession and ensure a future with talented Puerto Ricans at the forefront of scientific research and technology development. Here we present a group of neuroscientists and educators, the NeuroBoricuas, committed to revolutionize the scientific culture of Puerto Rico by incorporating neuroscience research training and inquiry-based activities in public and private schools. We carry out our vision through diverse methods, such as community outreach activities, where we promote neuroscience literacy using diverse learning activities. In parallel, we are designing a neuroscience course and textbook with educators to be implemented in schools. We also established neuroscience laboratories in $K$ 12 schools and trained science teachers to manage such laboratories, using equipment from the company "Backyard Brains". These laboratory experiences are integrated into the academic curriculum in high schools and the equipment is also available for students interested in designing their independent research projects. Lastly, we are expanding a network of committed scientists who partner with educators to help nurture future neuroscientists early in their academic endeavors. Here, we describe our trajectory and our approach to transform scientific education in Puerto Rico.

Keywords: Puerto Rico; Science; Community; Outreach; Backyard Brains; NeuroBoricuas. 


\section{Introduction}

Puerto Rico is an United States territory located in the Caribbean with an estimated population of 3.4 million inhabitants (US Census Bureau, 2016). Currently, the Island is going through an economic recession that threatens its development. It is estimated that about a thousand Puerto Ricans leave the island each week on one-way flights. It ranks as the seventh country with the greatest proportional loss of population in the world (Kilpatrick, 2015). Most migrants are young people seeking employment opportunities in the United States (Lopez-Alicea, 2015). In 2013, most Puerto Ricans who migrated outside Puerto Rico were between 5 to 29 years old (Puerto Rican Institute of Statistics, 2013). It was previously estimated that by 2020 about 300,000 Puerto Ricans would have emigrated (Marazzi Santiago, 2016), but this number is expected to be much higher now because of a sudden massive exodus $(100-200 \mathrm{~K})$ in response to last year's hurricanes, Irma and Maria (Torres-Gotay, 2017). Therefore, it is imperative that we produce initiatives that promote the retention of young talent of Puerto Rico.

Scientific research drives the development of technologies and acquisition of knowledge that benefits society. Research in biomedical sciences serves to characterize the workings of human physiology, to characterize diseases and to improve clinical treatments. Scientific research also serves as an excellent platform for education, where students learn in a dynamic context and are part of scientific discovery. In the process of scientific research, students learn to self-educate and undergo scientific reasoning, which is an excellent model for problem-solving. Therefore, scientific research serves as a platform to develop knowledgeable, well-informed citizens of public service, such as future educators, researchers, and health professionals.

An emerging field in life sciences, neuroscience, has been growing in Puerto Rico, such that 5 of 7 R01 / R37 grants (one of the major grants from the National Institutes of Health, USA) awarded in Puerto Rico are related to neurosciences. Some of the neuroscience topics currently researched in Puerto Rico are the neuronal mechanisms of drug addiction and alcohol dependence, neuronal basis of emotional learning and memory, organization of neural circuits that produce behavior, spinal cord regeneration, environmental pollution effects and behavior of endogenous animals of Puerto Rico, among other fields of neuroscience. Regrettably, Puerto Ricans in general are unaware of Puerto Rican contributions to science and technology. Students are unaware of scientific training opportunities. The idea that people need to leave Puerto Rico for quality education in science and engineering is a common misconception. In addition, many students are not familiar with the role of scientists or the academic track leading to a career in science.

To educate, guide and recruit future Puerto Rican scientists, we have developed an initiative where we empower the Puerto Rican youth to seek roles in science and technology 
development. We achieve this by merging the university academia with schools in Puerto Rico. The NeuroBoricuas initiative attained strong traction and it is succeeding in having a positive impact towards transforming the scientific culture in Puerto Rico. Here, we share how our initiative originated, how it grows, and how it can be replicated in other regions.

\section{History of NeuroBoricuas}

Long before it was known as Puerto Rico, the Taínos, the natives that lived in the island, called it Borikén. Boricuas, which stems from Borikén, is a popular way Puerto Ricans proudly self-identify. We therefore named our group, consisting of mainly neuroscientists, NeuroBoricuas. When we first started NeuroBoricuas, we were a group of ten people, including graduate students, postdoctoral scientists, technicians and professors. Our main goal was to train school teachers on how to incorporate neuroscience teachings in their courses, and to manage a neuroscience laboratory in their school. We presented our project proposal for the first time at the Annual Puerto Rico Neuroscience Conference in December 2016, where we recruited faculty and the members of our education panel in NeuroBoricuas. The first school we contacted was CROEM, a public boarding school in the west area of Puerto Rico that specializes in math and sciences. Students in this school are highly competitive and are considered among the top of the island, which made them suitable to be our pilot student cohort.
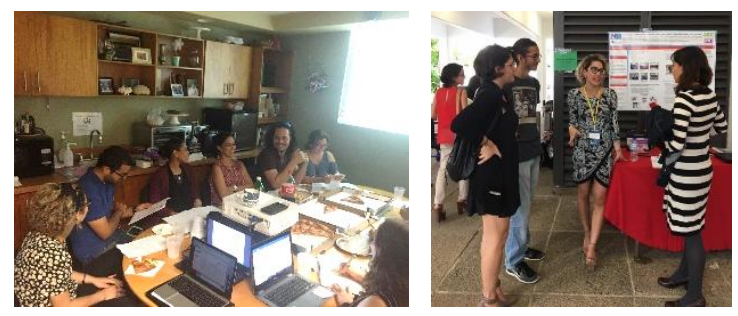

Figure 1. Inception of NeuroBoricuas. Left: The NeuroBoricuas Initiative started with a meeting at the University of Puerto Rico where we brainstormed ideas about how to empower students and educators to teach neuroscience in schools of Puerto Rico. Right: We shared our plans with other colleagues during the Puerto Rico Neuroscience Annual Conference, where many became new NeuroBoricuas.

We invited CROEM teachers and student leaders to the University of Puerto Rico School of Medicine in December 2016, where NeuroBoricuas gave lectures on basic neuroscience and a workshop on how to use equipment from Backyard Brains for their neuroscience laboratory. Using social media, we recurred to crowdfunding for acquiring the neuroscience laboratory equipment for CROEM. In January 2017, a team of NeuroBoricuas visited CROEM at Mayaguez, Puerto Rico, to install the first neuroscience laboratory in a Puerto Rican school ("Inauguran laboratorio de neurociencias", 2017). The inauguration started with remarks from representatives from the local government and the 
department of education, as well as world-renowned neuroscientist, whom endorsed our initiative. All the students and faculty from CROEM participated in the inauguration event.
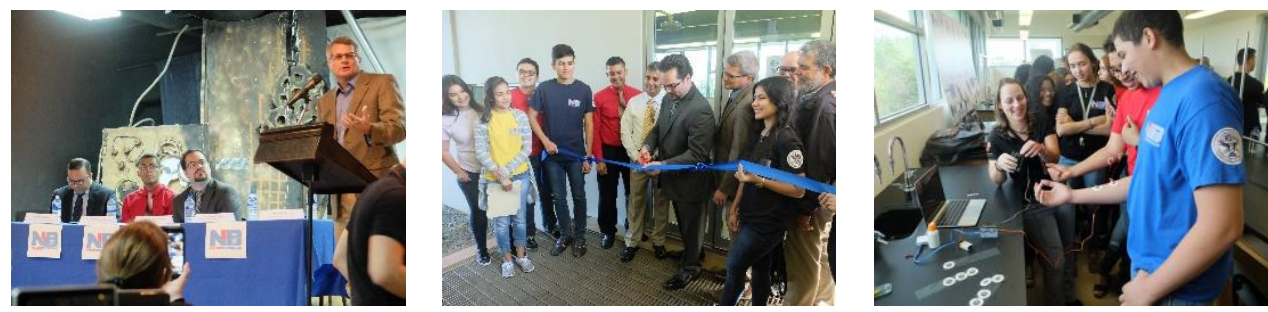

Figure 2. Inauguration of the first neuroscience laboratory in a Puerto Rican school. Left: Dr. Gregory J. Quirk, a prominent neuroscientist, lecturing the CROEM Community about the importance of science in Puerto Rico and endorsing the NeuroBoricuas initiative. Center: Ribbon-cutting of the neuroscience laboratory in CROEM. Right: CROEM students and NeuroBoricuas performing demonstrations of their newly-acquired neuroscience laboratory equipment during the inauguration.

A week after the lab inauguration, a team of NeuroBoricuas, had an outreach kiosk during the Fiestas de la Calle San Sebastián, one of Puerto Rico's most iconic street festivals. Dozens of NeuroBoricuas came together to deliver a community outreach to whole families that were attending the street festival in Old San Juan, Puerto Rico. The different presentation stations used equipment from Backyard Brains (detailed in the section below), neuroscience research and neuroanatomy with a human brain (Cruz, 2017).
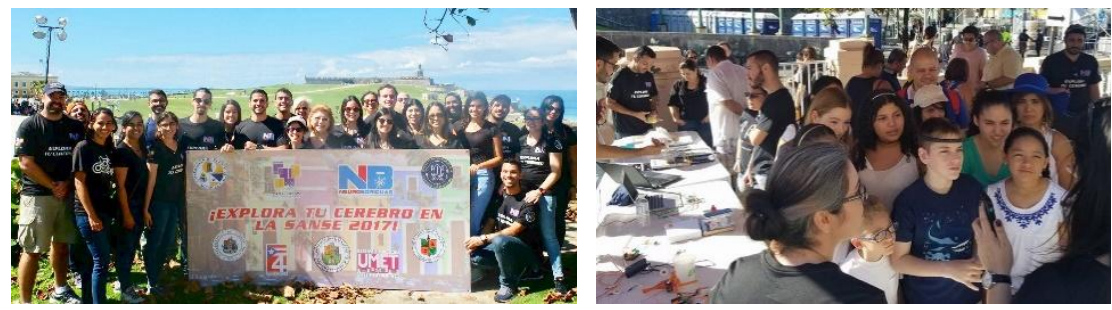

Figure 3. Neuroscience outreach in popular street festival in Puerto Rico. Left: NeuroBoricuas from different institutions gathered together to participate in an outreach activity targeting Puerto Rican families enjoying a massive street festival in Old San Juan, Puerto Rico. Right: Hundreds of festival attendees engaged in presentations from NeuroBoricuas and learned about the brain and neuroscience research.

Both the inauguration of CROEM's neuroscience laboratory and the outreach kiosk at Fiestas de la Calle were widely covered by the Puerto Rican press, both written and broadcasted. Both events were also shared on social media and inspired a significant number of people to join NeuroBoricuas. The press and social media exposure reached teachers, students and school principals that then reached out to us to collaborate with NeuroBoricuas. As of now, we have over 150 members of NeuroBoricuas in 18 universities in Puerto Rico, and 20 collaborating schools. 


\section{Partnering with Backyard Brains}

Because of our collaboration with Backyard Brains, partner schools and universities benefit from acquiring the lab equipment kit at a discounted and affordable price. The lab kit includes equipment for activities with people and insects. One component allows for the recording of nerve signaling in insects, generally in earthworms, or in the legs of cockroaches or grasshoppers (Marzullo and Gage, 2012; Dagda et al 2013). Electric activity of these nerves can be observed and measured through a free Backyard Brains application in a laptop, tablet or smartphone. Several types of experiments can be done with this set-up, such as measuring neural responses to sensorial stimuli, temperature changes and pharmacological agents, to name a few. Other components are suitable for non-invasive recording of neural signals that control the heart rhythm (electrocardiogram), neural activity from the brain cortex (electroencephalogram), and neural signals that control muscles (electromyogram). The kit also includes two modules of interface technology: a human-to-human interface and a human-to-machine interface. In the human-to-human interface module, neural signals from a person's arm motor neurons (sender) are registered in the interface, which has an electrical output that can stimulate the arm muscles of another person (receiver). The human-to-machine interface module allows a person to control a mechanic claw with neural signals from arm motor neurons. These interface modules serve as a great introduction to biotechnology. Additionally, the kit includes an apparatus that converts any smartphone into a high-power microscope.

These modules have a programmable Arduino integrated, such that these are modifiable. These Arduinos serve as a great opportunity for students to learn about programming, a skill highly relevant in scientific careers. Backyard Brains also provides the modules in disassembled parts, to allow students to engage in the challenge of building the equipment themselves. This serves as a great introduction to electronics and learning about how the system works. These modules are simple to use, such that high school students can become proficient in using these in a short time.

\section{NeuroBoricuas in K-12 Schools}

On our NeuroBoricuas' board, we have a School Coordinator who oversees all interactions between NeuroBoricuas and schools. Students, teachers, principals and parents reach out to us through our webpage, Facebook page, or email to inquire about collaborating with NeuroBoricuas. If students or parents make the approach, we ask them to provide us with the principal's or a teacher's contact information. We then proceed to discuss our collaboration agreement with the school representative. The collaboration agreement states that there must be a team of teachers and a team of students engaging in NeuroBoricuas activities. The team of teachers are trained to manage a neuroscience laboratory in their 
school by NeuroBoricuas volunteers. The team of students organizes a NeuroBoricuas' school club, which they manage themselves. In this club, students organize outreach activities within and outside of their school. They also discuss research articles in selfmoderated journal club discussions. The main objectives of these clubs are to empower students to engage in scientific inquiry and to start developing collaborative attitudes regarding research.

The NeuroBoricuas' club at CROEM school has already engaged in multiple outreach activities in a region often overlooked outside the metropolitan area. These students helped teach school educators to use the Backyard Brains laboratory equipment in the NeuroBoricuas workshop intended for teachers from schools in the west area of Puerto Rico. This was a powerful sight; students felt empowered to teach what they had recently learned, including their teachers. Teachers not only learned about neuroscience and the equipment, but also about what Puerto Rican students can achieve. These CROEM students also showcased the neuroscience laboratory equipment to the press during the lab inauguration, which served as evidence to Puerto Rican educators that students are ready for this next step in their education.
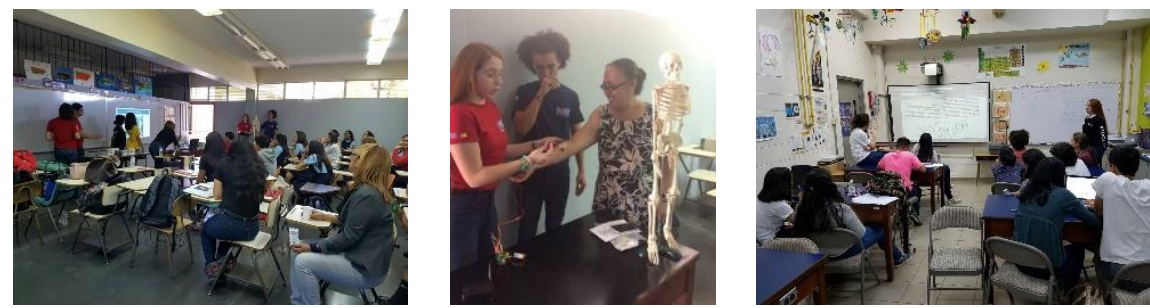

Figure 4. NeuroBoricuas Students' club at CROEM high school. Left: Students from the NeuroBoricuas club at CROEM visiting a school to teach students about neuroscience. Center: The students also taught the teachers about neuroscience. Right. The students discussing research articles in a journal club meeting moderated by themselves. This journal club is commonly practiced by research teams in their laboratories.

We have a team of NeuroBoricuas that majored in education that are designing a neuroscience introductory course for high schools. This course will include a laboratory component, so students will learn about neuroscience in the classroom and with hands-on experiments using their laboratory equipment. We are, also, working on a textbook for this course through a collaboration where Puerto Rican neuroscientists who are coming together to collaborate to cowrite the different chapters. 

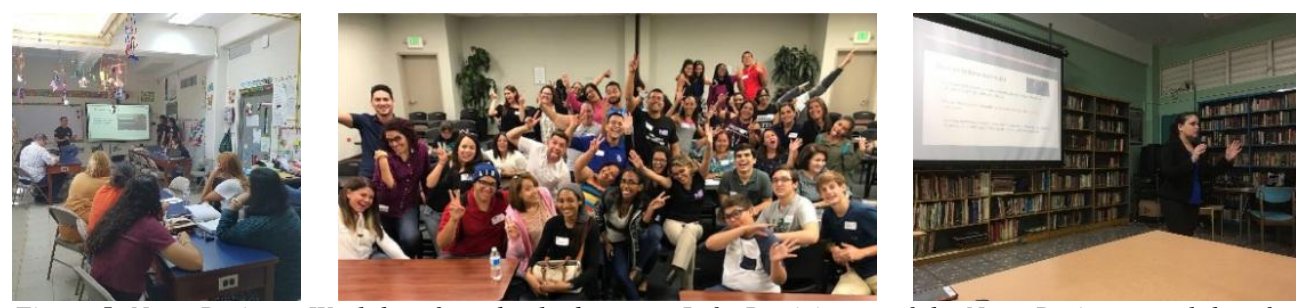

Figure 5. NeuroBoricuas Workshop for school educators. Left: Participants of the NeuroBoricuas workshop for teachers from the west of Puerto Rico. Led by Dr. Miguel Mendez-Gonzalez. Center: Participants of the NeuroBoricuas workshop for teachers from the north and east of Puerto Rico. Led by Zarcaly Quintero and Dr. Manuel Diaz-Rios. Right. Participants of the NeuroBoricuas workshop for teachers from the south of Puerto Rico. Led by Dr. Bermary Cruz and Dr. Maria de Jesus.

\section{NeuroBoricuas Chapters in Universities}

In our NeuroBoricuas' board, we have a University Coordinator that oversees all interactions between NeuroBoricuas and university chapters. One of our major targets are university students and professors. We encourage them to organize an institutional NeuroBoricuas chapters, where as a student's association they can convene and expand the mission of NeuroBoricuas. Members of these chapters actively participate in outreach activities and in workshop for teachers that recently joined NeuroBoricuas. We use questionnaires to assess the efficacy of our teaching methods and the teachers' appraisal. Additionally, they host visitors in research labs to learn about neuroscience research in Puerto Rico and they visit schools and communities to teach neuroscience as well. They also serve as judges at scientific fairs in schools and assist students with their research projects. These chapters also recruit schools nearby their institutions and oversee the training of educators of to manage the neuroscience laboratory. Another role these NeuroBoricuas have is to represent our initiative at different symposia and increase our reach.
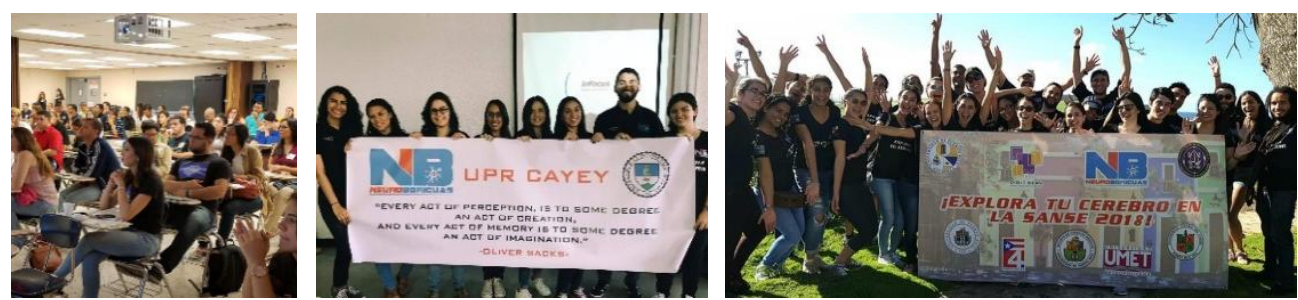

Figure 6. NeuroBoricuas Workshop for university students and professors. Left: First massive workshop where over a hundred volunteers became NeuroBoricuas as they received training on how to use Backyard Brains equipment and perform neuroscience outreach activities. Center: Initiation of the NeuroBoricuas Chapter at the University of Puerto Rico-Cayey. Right. New NeuroBoricuas joined the neuroscience outreach activity in the San Sebastian street festival in January 2018. 


\section{Conclusions and Future Directions}

Here, we propose a model in which the university academia can merge with schools to enhance scientific education. Our long-term goal is that scientific inquiry will reach people's homes through students, and science and technology will be highly regarded by Puerto Ricans. This shift in scientific culture would result in a government shift as well, because people would start to elect politicians that prioritize education and the advancement of science. Soon, we will organize a NeuroBoricuas symposium where the clubs and chapters can meet and share their results and experiences. We propose to collaborate with engineering departments to teach programming and technology skills in our workshops. Regarding our reach, we plan to create alliances with scientists from other Latin-American countries with the same goals, share our initiative and organize a LatinAmerican Brain Week, where partner schools and universities will combine efforts in neuroscience outreach activities. Lastly, we will continue to recruit Puerto Ricans living abroad, so they can have an impact in their respective communities.

\section{Acknowledgements}

We thank Dr. Gregory J. Quirk, Dr. Daniel Colon-Ramos and Dr. Mark Miller for their support. We thank Tim Marzullo, from Backyard Brains, for supporting NeuroBoricuas. We also thank Palabreria, Digi-Serv and Puerto Rico 4.0 for their constant support. We thank all the NeuroBoricuas that selflessly work hard for a better Puerto Rico. This work has been supported by generous donations from the Puerto Rican people, a grant from the University of Puerto Rico Medical Sciences Campus' Chancellor's office, and the Grass Foundation.

\section{References}

Inauguran laboratorio de neurociencias (2017). El Nuevo Dia. January 12, 2017. [https://www.elnuevodia.com/ciencia/ciencia/nota/inauguranlaboratoriodeneurociencias $-2280435 /]$

Cruz F. (2017). Los NeuroBoricuas de la CROEM en la Sanse. El Post Antillano. January 19, 2017. [http://elpostantillano.net/economia-solidaria/18696-2017-01-19-13-1605.html].

Dagda RK, Thalhauser RM, Dagda R, Marzullo TC, Gage GJ. (2013). Using crickets to introduce neurophysiology to early undergraduate students.J Undergrad Neurosci Educ. 2013 Oct 15;12(1):A66-74. eCollection 2013. 
Kilpatrick K. (2015). Puerto Rico's economy, crime to blame for middle class exodus. Al Jazeera. July 28, 2015. [http://alj.am/lwny].

López Alicea K. Publican el Perfil del Migrante. (2015) El Nuevo Dia. February 8, 2015. [https://www.elnuevodia.com/noticias/locales/nota/publicanelperfildelmigrante2005257/]

Marazzi Santiago M. (2016). Migración neta a los Estados Unidos alcanza record histórico. Instituto de Estadísticas de Puerto Rico. May 1, 2016. [http://www.estadisticas.gobierno.pr/iepr/LinkClick.aspx?fileticket=38FafYENIXg\%3D $\&$ tabid=39\&mid=590].

Marzullo TC, Gage GJ. (2012). The SpikerBox: a low cost, open-source bioamplifier for increasing public participation in neuroscience inquiry. PLoS One. 2012;7(3):e30837. doi: 10.1371/journal.pone.0030837. Epub 2012 Mar 21.

Torres-Gotay B. Dramática reducción poblacional luego del paso de María. El Nuevo Dia. November 4 , 2017. [https://www.elnuevodia.com/noticias/locales/nota/dramaticareduccionpoblacionalluego delpasodemaria-2371581/].

U.S. Census Bureau (2016). Population of Puerto Rico. [https://www.census.gov/data/datasets/2017/demo/popest/detail-puerto-rico.html]. 